\title{
LOS COMISIONADOS PARLAMENTARIOS AUTONOMICOS Y EL CONTROL DE LA ADMINISTRACION LOCAL
}

\author{
POR \\ ANTONIO EMBID IRUJO \\ Catedrático de Derecho administrativo
}

\begin{abstract}
SUMARIO: I. INTRODUCCIÓN.-II. La RELACIÓN DE LOS COMISIONADOS PARLAMENTARIOS AUTONÓMICOS CON LAS ADMINISTRACIONES LOCALES: DOS POSIBLES FORMAS DE ABORDAR LA CUESTIÓN. - III. LA REGULACIÓN ESTATUTARIA Y ORDINARIA DE LOS PODERES DE SUPERVISIÓN DE LOS Comisionados Parlamentarios autonómicos sobre la administración local: A) El planteamiento en los Estatutos de Autonomía; B) La ampliación de la Administración, objeto de supervisión por la mayoría de las leyes autonómicas.-IV. LA ADMINISTRACIÓN LOCAL, OBJETO DE SUPERVISIÓN, Y LA LEY 36/1985, DE 6 DE NOVIEMBRE.-V. LA LEGITIMIDAD CONSTITUCIONAL DE LA LEGISLACIÓN AUTONÓMICA SOBRE LA SUPERVISIÓN DE LA Administración local: A) El poder de autoorganización de las comunidades Autónomas y su extensión; B) La posición de la Administración local en las Comunidades Autónomas.-VI. REFLEXIONES fINALES
\end{abstract}

\section{INTRODUCCION}

Recientemente he llevado a cabo un estudio sobre el régimen jurídico de los Comisionados Parlamentarios Autonómicos (en adelante CPA) desde la perspectiva fundamental de la actividad de control de la Administración pública que llevan a cabo con motivo de su tarea de defensa de los derechos fundamentales y de las libertades públicas (1). En ese estudio se dedicaba un apartado especial a las posibilidades de supervisión de las Administraciones locales defendiéndose en el mismo, con variedad de matices y argumentos, una amplia capacidad de intervención de los CPA sobre las Administraciones locales sitas en su territorio respectivo

(1) Mi trabajo lleva como título El control de la Administración Pública por los Comisionados Parlamentarios Autonómicos, y va a ser objeto de próxima publicación por el INAP, Madrid. En el mismo, y bajo la rúbrica CPA, agrupo el estudio de las figuras que semejantes al Defensor del Pueblo han sido creadas por diversos Estatutos de Autonomía y, posteriormente, reguladas por Leyes ordinarias de CC AA. Son estas figuras las siguientes: El Defensor del Pueblo andaluz (Ley andaluza de 1 de diciembre de 1983), el "Sindic de Greuges» catalán (Ley de 20 de marzo de 1984), el Valedor del Pueblo gallego (Ley de 5 de junio de 1984), el Diputado del Común canario (Ley de 12 de febrero de 1985), el Ararteko vasco (Ley de 27 de febrero de 1985) y el Justicia de Aragón aragonés (Ley de 27 de junio de 1985). De ellos, las instituciones gallega y vasca aún no han entrado en funcionamiento por faltar la elección de sus primeros titulares. Al margen de estas seis leyes, también los Estatutos valenciano y balear regulan instituciones semejantes, faltando hasta este momento la necesaria legislación ordinaria de desarrollo. 
si, por supuesto, así lo autorizaba el ordenamiento jurídico regulador de cada CPA. Lo particular del tratamiento que a ese tema se daba venía también determinado por el hecho de que la cuestión se encontraba a examen ante el Tribunal Constitucional, dado que se habian interpuesto dos recursos de inconstitucionalidad en los que el tema fundamental era, precisamente, el de la supervisión de las Administraciones locales. Uno de los recursos fue el interpuesto por el Presidente del Gobierno contra la Ley 4/1985, de 27 de junio, reguladora del Justicia de Aragón (2); el otro, el que el Parlamento catalán interpuso contra la Ley 36/1985, de 6 de noviembre, por la que se regulan las relaciones entre la institución del Defensor del Pueblo y las figuras similares en las distintas Comunidades Autónomas.

Pues bien, acaba de aparecer la setencia que resuelve el primero de los recursos mencionados. Se trata de la STC 142/1988, de 12 de julio de 1988 («BOE» de 8 de agosto de 1988). En ella, aparte de solucionarse de forma positiva para la ley aragonesa la práctica totalidad de los artículos a los que se imputaba el vicio de inconstitucionalidad, se contiene una determinada doctrina sobre la supervisión de la Administración local por los CPA coincidente con la de la Ley 36/1985, de 6 de noviembre, impugnada por el Parlamento catalán, por lo que es de suponer que la próxima aparición de la sentencia que resuelva ese recurso repetirá la doctrina creada por la que aquí se comenta. Pues bien, el motivo de este trabajo es el de mostrar la insatisfacción que produce la lectura de la Sentencia del Tribunal Constitucional que, aun afirmando la constitucionalidad de la ley aragonesa, interpreta el precepto impugnado de una forma determinada (3) que prácticamente viene a vaciar de contenido la posible actividad del CPA aragonés $-y$ habría que pensar del resto, aunque ello se tratará en las conclusiones de este comentario- reduciendo a lo casi simbólico su poder de supervisión de las distintas Administraciones locales. Veamos más despacio y en el siguiente punto los terminos del problema planteado y las dos posibles soluciones al mismo.

(2) Se interpuso en octubre de 1985 contra bastantes preceptos de esta Ley: el 2.3, y en conexión con el mismo, los artículos 19.2, 21.1 y 31.2, asi como contra los articulos 12.2, 21.2 y 2.2. La impugnación llevó consigo la suspensión durante cinco meses de los preceptos controvertidos levantada por el Tribunal Constitucional por Auto de 6 de marzo de 1986.

(3) El Tribunal Constitucional acude a un método ya tradicional en su jurisprudencia, como es el de las sentencias interpretativas, para evitar la declaración de inconstitucionalidad, con lo que se coopera a un saludable principio de conservación de la norma. En algunos casos, sin embargo, la interpretación "con arreglo a la Constitución» de un precepto, puede llevar en el plano de la práctica a su inutilidad por vaciamiento de contenido, con lo que los efectos, en última instancia, se asemejan a los de la declaración de inconstitucionalidad. Me da la impresión. como intentaré demostrar en el trabajo, que eso es lo que sucede en este caso. 


\section{LA RELACION DE LOS COMISIONADOS PARLAMENTARIOS AUTONOMICOS CON LAS ADMINISTRACIONES LOCALES: DOS POSIBLES FORMAS DE ABORDAR LA CUESTION}

La Sentencia del Tribunal Constitucional que tratamos, aun referida a un CPA específico, el aragonés, presenta una doctrina extendible perfectamente al resto. Dejando para más adelante las citas a otras legislaciones, veamos ahora el precepto de la ley aragonesa al que se le imputaba vicio de inconstitucionalidad. Dice así el artículo 2.2:

«EI Justicia de Aragón podrá también supervisar la actuación de los Entes locales aragoneses en todo lo que afecte a materias en las que el Estatuto de Autonomía atribuya competencia a la Comunidad de Aragón.»

La voluntad del precepto es, pues, clara. Se configura una amplia capacidad de intervención sobre las Administraciones locales, tan amplia como pueda ser la actuación de esas Corporaciones locales en las materias atribuidas a la competencia de la Comunidad Autónoma de Aragón. Un ejemplo concreto ilustra claramente lo que se quiere decir: Dado que el urbanismo es una de las materias en las que el Estatuto de Autonomía atribuye competencias a la Comunidad aragonesa (art. 35.1.3), cualquier actuación urbanística de un municipio aragonés sería susceptible -caso de que mediante ella pudiera verse afectado un derecho fundamental - libertad pública- de supervisión por el Justicia de Aragón, ejercitando su competencia de defensa de los derechos y libertades públicas.

Esta interpretación o lectura literal del precepto va a ser, sin embargo, negada por el Tribunal Constitucional, quien indica que la única forma de salvar la constitucionalidad del precepto es restringir su extensión. En efecto, partiendo de que el artículo 33 del Estatuto de Autonomía de Aragón, creador de la institución del Justicia, sólo atribuye a éste el control de la Administración de la Comunidad Autónoma, se habría producido una ampliación -ilegítima para el Tribunal Constitucional- de su ámbito de competencias por la Ley de 27 de junio de 1985 al incluir también a los Entes locales dentro de sus potestades de supervisión. Para salvar la constitucionalidad del artículo 2.2 de esta Ley hay que llevar a cabo una determinada interpretación «con arreglo a la Constitución» del mismo. Veámoslo en palabras del Tribunal Constitucional: 
"En conclusión, el artículo 2.2 de la Ley $4 / 1985$, de 27 de junio, no es inconstitucional ni desborda los límites del artículo 33.2 del EAA siempre que se interprete que las facultades de supervisión del Justicia de Aragón sobre la actuación de los Entes locales aragoneses sólo podrán ejercerse en materias "en las que el Estatuto de Autonomía atribuya competencias a la Comunidad Autónoma de Aragón" (art. 2.2) y respecto de las que ésta haya, además transferido o delegado en los Entes locales. Sólo así puede entenderse que el Justicia se mantiene dentro del ámbito de actuación de supervisión de la actividad de la Administración de la Comunidad Autónoma que le confiere el artículo 33.2 del EAA.»

La clave de la forma de interpretación realizada por el Tribunal Constitucional se halla en las palabras que aparecen en cursiva. No es, por tanto, cualquier actuación llevada a cabo por las Corporaciones locales dentro del ámbito de materias en que el Estatuto de Autonomía atribuye competencias a la Comunidad Autónoma la que es susceptible de supervisión, sino solamente aquella competencia de la Comunidad Autónoma (habrá que entender de la Administración de la Comunidad Autónoma) que haya sido transferida o delegada por el medio previsto en el ordenamiento jurídico, a una Corporación local. No es, así y volviendo al ejemplo anterior, cualquier actuación urbanística de una Corporación local la susceptible de supervisión, sino solamente la llevada a cabo como consecuencia de una transferencia o delegación de una competencia urbanística atribuida por el ordenamiento jurídico a la Administración autonómica y que, como consecuencia de esa transferencia o delegación, pase al ámbito de disposición de la Corporación local.

Se comprenderá, pues, que la interpretación del precepto que postula el Tribunal Constitucional y que tras su Sentencia es la única posible, es extremadamente restrictiva. En muchos casos, además, será imposible que en algunas materias pueda darse la mínima supervisión de la actividad de los Entes locales por el CPA, pues -como sucede en la mayor parte del urbanismo- las funciones de la Administración autonómica sobre una materia pueden ser solamente de control (aprobaciones, autorizaciones, etc.), y como tales, insusceptibles de transferencia o delegación.

Pero no es el aspecto de las consecuencias prácticas lo que me preocupa a la hora de la redacción del presente trabajo. A fin de cuentas -podría reprocharse a un trabajo de perspectivas exclusivamente jurídicas - introducir elementos como el anteriormente nombrado es insustancial o intrascendente desde planteamientos 
jurídicos $y$, quizá, solamente valorable desde otro tipo de enfoque. No, lo que pretendo decir es que hubiera sido posible que el Tribunal Constitucional hubiera aceptado la constitucionalidad del precepto discutido sin esta interpretación restrictiva, porque existen suficientes argumentos jurídicos para mantener que su lectura literal -sin interpretaciones- es adecuada a la Constitución.

Para llegar a esa conclusión comenzaré por llevar a cabo un repaso de los preceptos estatutarios y de las leyes ordinarias reguladoras de los CPA en lo que se refiere al poder de supervisión sobre los Entes locales (III). Los preceptos referidos se contrastarán con lo regulado por la Ley $36 / 1985$, de 6 de noviembre, por la que se regulan las relaciones entre la Institución del Defensor del Pueblo y las figuras similares en las distintas Comunidades Autónomas, de planteamientos bien distintos, coincidentes con la Sentencia que aquí se trata (IV). En el siguiente punto se razonará la legitimidad constitucional de los preceptos de la legislación autonómica (V) para pasar, por fin, a establecer una serie de reflexiones (VI).

\section{LA REGULACION ESTATUTARIA Y ORDINARIA DE LOS PODERES DE SUPERVISION DE LOS COMISIONADOS PARLAMEN- TARIOS AUTONOMICOS SOBRE LA ADMINISTRACION LOCAL}

\section{A) El planteamiento en los Estatutos de Autonomía}

Es lo normal en los Estatutos de Autonomía que recogen la figura del Comisionado parlamentario, que refieran su actividad a la supervisión de la Administración autonómica respectiva. Esto sucede en el caso del Estatuto catalán (4), andaluz (5), aragonés (6), canario (7) y balear (8). Una redacción especial y más indeterminada

(4) «Sin perjuicio de la institución prevista en el artículo 54 de la Constitución y de la coordinación con la misma, el Parlamento podrá nombrar un "Sindic de Greuges" para la defensa de los derechos fundamentales y las libertades públicas de los ciudadanos, a cuyos efectos podrá supervisar las actividades de la Administración de la Generalidad. Una Ley de Cataluña establecerá su organización y funcionamienton (art. 35).

(5) El texto del artículo 46 del Estatuto de Andalucia es muy semejante al catalán citado en la nota anterior, con la diferencia de sustituir la expresión "Sindic de Greuges" por la de Defensor del Pueblo, y la de Administración de la Generalidad por Administración autonómica.

(6) «En el ejercicio de su función, el Justicia de Aragón podrá supervisar la actividad de la Administración de la Comunidad Autónomai) (art. 33-2 del Estatuto).

(7) «El Parlamento podrá nombrar un "Diputado del Común" para la defensa de los derechos fundamentales y las libertades públicas de los ciudadanos, y supervisará las actividades de la Administración de la Comunidad Autónoma, de acuerdo con lo establecido en la Ley Orgánica del Defensor del Pueblo. Una Ley del Parlamento de Canarias establecerá su organización y funcionamiento" (art. 13).

(8) «El Parlamento, mediante una Ley, podrá crear una institución similar a la prevista en el artículo 54 de la Constitución para la defensa de los derechos y deberes fundamentales, asi como para supervisar e investigar las actividades de la Administración de la Comunidad Autónoma. Dicha institución actuará en coordinación y cooperación con el Defensor del Pueblo» (art. 29). 
adopta el Estatuto vasco, para quien esta figura -que no se denomina- puede cumplir las funciones del «Defensor del Pueblo» $y$ «cualesquiera otras que el Parlamento vasco pueda encomendarle» (art. 15), expresándose con terminología muy semejante el Estatuto gallego (9). El Estatuto valenciano, por su parte, entrega al Síndico de Agravios la facultad de velar por los derechos reconocidos en el título I de la CE, uen el ámbito territorial y competencial de la Comunidad Valenciana» (art. 24), lo que es bastante vago, en verdad.

Lo que importa destacar de toda esta enumeración es la amplia mayoría que entre los Estatutos existe a la hora de considerar a la Administración autonómica como la única objeto de supervisión $y$, a su vez, el carácter vago e impreciso del resto de los Estatutos.

B) La ampliación de la Administración objeto de supervisión por la mayoría de las leyes autonómicas

Curiosamente, sin embargo, la mayoría de las leyes autonómicas promulgadas van a ampliar las posibilidades de supervisión del CPA. Sólo la Ley andaluza permanece fiel a la idea de considerar que únicamente la Administración autonómica será la supervisada por el Defensor del Pueblo andaluz (art. 1.1), pero en el resto, como decía, se produce esa ampliación y en el caso del País Vasco, cuyo Estatuto era bastante impreciso, como se recordará, las novedades que se producen por la legislación ordinaria van también en la línea ampliatoria notada (10).

Hay prácticamente unanimidad en señalar cuál es la Administración que debe ser objeto de las potestades de supervisión del CPA al margen de la autonómica: se trata de la Administración local. Las leyes autonómicas utilizan diversas fórmulas para referirse a la supervisión de la Administración local, fórmulas que voy a señalar textualmente.

Así la Ley catalana indica que el "Síndic de Greuges»:

«Supervisa también la actuación de los entes locales de Cataluña en todo lo que afecta a las materias en que el

(9) "Corresponde a la Comunidad Autónoma la creación y organización, mediante Ley de su Parlamento, y con respecto a la Institución del Defensor del Pueblo, establecida en el artículo 54 de la Constitución, de un órgano similar que, en coordinación con aquélla, ejerza las funciones a las que se refiere el mencionado artículo y cualesquiera otras que el Parlamento de Galicia pueda encomendarle" (art. 14).

(10) La misma Ley vasca, cuando habla de la supervisión de la "Administración común de la Comunidad Autónoma» añade, uincluida la Administración periférica de la misma, sus organismos autónomos, sociedades públicas y demás entes públicos que de ella dependan» [art. 9 a)] 
Estatuto de Autonomía de Cataluña otorga competencias a la Generalidad» (art. 1.1) (11).

La Ley canaria es más simple e indica que el Diputado del Común:

«Supervisa la actividad de (la Administración) local cuando ejercite competencias de la Comunidad Autónoma» (art. 1.1).

La fórmula de la Ley vasca es amplísima. Su artículo 9 prevé que los poderes de investigación del Ararteko se extenderán a:

«b) La Administración de los territorios históricos, incluidos sus organismos autónomos, sociedades públicas y demás entes públicos dependientes de la misma.

c) La Administración local, incluidos sus organismos autónomos, sociedades públicas y demás entes públicos que de ella dependan en el ámbito competencial establecido por el artículo 10.4 del Estatuto de Autonomía.»

La Ley aragonesa tiene un dictado que ya he reseñado en el punto anterior (II) y que está fuertemente influido por la redacción de la Ley catalana.

Sólo la Ley gallega es una excepción a lo hasta aquí dicho, pues aunque lleva a cabo una ampliación de competencias respecto a lo que su Estatuto -bastante impreciso- indica, no lo hace nombrando a la Administración local, sino a empresas públicas y entes dependientes de la Administración autonómica (12).

Práctica unanimidad de las leyes autonómicas en la voluntad ampliatoria del ámbito de supervisión del respectivo CPA respecto

(11) Como se habrá comprobado por la lectura del precepto catalán, su contenido es prácticamente idéntico al del precepto correspondiente de la Ley aragonesa uinterpretado" por el Tribunal Constitucional en la Sentencia que se comenta en este trabajo.

(12) No acaba con lo nombrado en el texto la voluntad ampliatoria de las Leyes autonómicas consideradas. Este trabajo no es el lugar oportuno para realizar amplias citas -lo he hecho en mi libro El control... de próxima publicación-, pero no quiero concluir el punto sin indicar el aparente crédito sin límites de cuantía que las Leyes autonómicas otorgan a las futuras figuras de los CPA dadas las amplísimas competencias que les otorgan dentro del poder de supervisión. Un buen ejemplo lo será el de la Ley del Ararteko vasco -institución, por cierto, aún no puesta en marcha-, cuyo artículo 9 d), indica que los poderes de supervisión se extienden también a: «Los servicios gestionados por personas físicas o jurídicas mediante concesión administrativa $y$, en general, a cualquier organismo o entidad, persona jurídica o privada que actúe en servicio público, estando sometida, al mismo tiempo, a algún tipo de control o tutela administrativa en todo lo que afecte a las materias en que el Estatuto de Autonomía otorga competencias a la Comunidad Autónomal. En mi libro citado he intentado construir un único criterio de intervención de los CPA, basándolo en la afección a los derechos fundamentales y libertades públicas y la existencia en un determinado organismo de la «función» de administrar. Para más detalles me remito al capítulo IV de este libro. 
a lo literalmente indicado por cada Estatuto de Autonomía. La referencia, en cuanto a lo que ahora nos importa, la Administración local viene marcada por el ámbito competencial de la Comunidad Autónoma. Así aparece en las leyes que consideramos con fórmulas distintas, pero siempre, como indico, con la cita de las "competencias" que el Estatuto otorgue a la Comunidad Autónoma. Precisamente es ésa la fórmula objeto de interpretación $-y$ bien restrictiva, como he dicho- por el Tribunal Constitucional en la Sentencia que aquí se comenta, pero la manera de interpretar del Tribunal Constitucional había sido ya anticipada por una ley estatal de elaboración bien significativa. Contemplemos la Ley y su procedimiento parlamentario en el siguiente punto.

\section{LA ADMINISTRACION LOCAL OBJETO DE SUPERVISION Y LA LEY 36/1985, DE 6 DE NOVIEMBRE}

Si hasta ahora nos hemos estado moviendo en un terreno jurídico marcado por el ejercicio de la potestad legislativa de las Comunidades Autónomas, la Ley 36/1985, de 6 de noviembre, por la que se regulan las relaciones entre la Institución del Defensor del Pueblo y las figuras similares en las distintas Comunidades Autónomas, nos aporta la primera regulación por ley ordinaria estatal de los CPA.

Ley estatal, pero que, sin embargo, proviene del ejercicio de la iniciativa legislativa prevista en el artículo 87-2 de la Constitución Española por tres Parlamentos de Comunidades Autónomas: el Parlamento catalán, el andaluz y las Cortes de Aragón (13). En otro lugar he estudiado más pormenorizadamente el ejercicio de esta iniciativa legislativa y sus avatares y a él me remito (14), pero ahora sólo quiero resaltar el doble contenido de esta iniciativa legislativa que, finalmente, se convertiría en ley y que trasciende al mismo largo título de la misma: no se trata solamente de prever las relaciones entre la figura constitucional del Defensor del Pueblo y los CPA (a lo que se dedica su art. $2^{\circ}{ }^{\circ}$ ), sino también de otorgar a los CPA una serie de privilegios y garantías penales y procesales (inmunidad, inviolabilidad, libertad de correspondencia con presos, etc.) que se juzgaban imprescindibles para que los CPA desarrollaran adecuadamente su función y que no podian ser otorgadas por

(13) Sobre la iniciativa legislativa de las "Asambleas" de las Comunidades Autónomas me remito a A. EMBID IRUJO: Los Parlamentos territoriales, ed. Tecnos, Madrid, 1987, pp. 214 y ss., con toda la literatura alli citada.

(14) Cfr. El control..., op. cit., capítulo III. 
las leyes autonómicas en virtud de la atribución constitucional al Estado de esta potestad (art. 149.1.6).

No es ahora el aspecto de concesión de privilegios y garantías el que nos interesa, sino el de previsión de cooperación entre Defensor del Pueblo y CPA. Los tres Parlamentos suscriptores de la iniciativa tienen conciencia de la -ahora sabemos- aparente duplicidad de órganos con competencia supervisora de la Administración local de las Comunidades Autónomas afectadas: el Defensor del Pueblo la tendría por directa atribución constitucional (art. 54 y, por supuesto, Ley Orgánica del Defensor del Pueblo) y también los CPA en virtud de lo dispuesto por las respectivas leyes autonómicas (sólo en los casos catalán y aragonés, el andaluz, como antes se dijo, seguía también en la ley ordinaria con la limitación estatutaria a la Aministración autonómica). Se intentaba entonces facilitar la acción de todas las instituciones previendo un sistema de colaboración que desembocaría en la firma entre el Defensor del Pueblo y cada CPA de un acuerdo que previera las posibilidades de intervención respectiva sobre aquellas Administraciones donde cupiera duplicidad de intervenciones (15). Una de ellas era, claro, aparte de la Autonómica, la Administración local. Pues bien, el texto del artículo 2.1 de la proposición de ley presentada al Congreso de los Diputados decía así:

"La protección de los derechos y libertades de la Constitución y la supervisión a estos efectos de la actividad de la Administración pública propia de cada Comunidad Autónoma, así como de las Administraciones de los Entes locales, se podrá realizar de oficio o a instancia de parte por el Defensor del Pueblo y el Comisionado Parlamentario Autonómico en régimen de cooperación, según lo establecido en el apartado segundo de este artículo, en todo aquello que afecte a materias sobre las cuales se atribuyan competencias a la Comunidad Autónoma en la Constitución $y$ en el repectivo Estatuto de Autonomía y sin mengua de lo establecido en cuanto a facultades del Defensor del Pueblo por la Constitución y por la Ley Orgánica 3/1981, de 6 de abril.»

(15) Con estas palabras prevé el artículo 2.2 de la Ley citada el sistema de cooperación. Debo advertir, previamente a su cita, que el precepto permaneció intocado a lo largo de toda la tramitación parlamentaria: «A fin de desarrollar y concretar adecuadamente la colaboración y coordinación entre el Defensor del Pueblo y los Comisionados Parlamentarios Autonómicos, se concertarán entre ellos acuerdos sobre los ámbitos de actuación de las Administraciones públicas objeto de supervisión, los supuestos de actuación de los Comisionados Parlamentarios, las facultades que puedan ejercitar, el procedimiento de comunicación entre el Defensor del Pueblo y cada uno de dichos Comisionados Parlamentarios y la duración de los propios acuerdos." 
La proposición de ley era, por tanto, congruente con el texto de las leyes ordinarias aprobadas o en trámite de aprobación en el momento de presentación del texto por cada Parlamento territorial. La proposición de Ley, sin embargo, variaría sustancialmente de contenido en este tema durante su tramitación parlamentaria (16), de tal forma que el texto final del artículo 21.1 -ahora ya Ley- dirá lo siguiente:

"La protección de los derechos y libertades reconocidos en el título I de la Constitución y la supervisión a estos efectos de la actividad de la Administración autónoma, así como de las Administraciones de los Entes locales cuando actúen en ejercicio de competencias delegadas por aquélla, se podrá realizar de oficio o a instancia de parte, por el Defensor del Pueblo y el Comisionado Parlamentario Autonómico en régimen de cooperación, según lo establecido en el apartado segundo de este artículo, en todo aquello que afecte a materias sobre las cuales se atribuyan competencias a la Comunidad Autónoma en la Constitución y en el respectivo Estatuto de Autonomía, y sin mengua de lo establecido en cuanto a facultades del Defensor del Pueblo por la Constitución y por la Ley Orgánica 3/1981, de 6 de abril.»

Creo que las palabras que aparecen en cursiva en los dos textos son representativas de la intención de cada uno de ellos. Y del resultado final, por supuesto, bien restrictivo de las posibilidades de intervención del Comisionado Parlamentario. Estas, en efecto, se restringen claramente, pues la fórmula del «ejercicio de competencias delegadas» supone, ni más ni menos, que no basta con la atribución de competencias estatutarias a la Comunidad Autónoma sobre una materia como para que cualquier actividad de los municipios, desarrollada dentro del marco jurídico de esa materia, caiga dentro de las potestades supervisoras del Comisionado Parlamentario Autonómico. Por el contrario, esta intervención solamente podría tener lugar cuando la Comunidad Autónoma hubiera delegado una facultad específica de esa materia en la Administración local -provincial o municipal- correspondiente. Como he indicado ya antes, esta posibilidad es bien remota en aquellas materias donde las competencias de las Comunidades Autónomas son de control, supervisión, inspección, aprobación de

(16) El cambio tendria lugar en el Senado, y aparece ya en el dictamen de la Comisión constitucional de éste. Cfr. Boletín Oficial de las Cortes Generales-Senado, núm. 280, d), serie II, de 5 de octubre de 1985. 
actos de las Administraciones locales y, por tanto, en si mismas indelegables. Este criterio igualmente arroja otro tipo de dificultades -fundamentalmente de imprecisión sobre el régimen de supervisión- al que me referiré más tarde en las reflexiones finales de este trabajo.

Es así más que clara la voluntad restrictiva del texto de la Ley $36 / 1985$, de 6 de noviembre. Voluntad restrictiva respecto a los planteamientos legales autonómicos e igualmente respecto al mismo origen y espíritu que animaba la presentación de la proposición de ley por los tres parlamentos citados. Una proposición de Ley que se quería fundamentalmente defensora de las competencias y posibilidades de actuación de los CPA, imaginando para ello un régimen de cooperación basado en la suscripción de acuerdos con el Defensor del Pueblo que no supusiera merma de las competencias de este último y que evitara duplicaciones burocráticas inútiles y dificultades de todo tipo. El resultado final, por ello, era ciertamente paradójico y contrario a la voluntad de los poseedores de la iniciativa legislativa. No es de extrañar, por tanto, la presentación de un recurso de inconstitucionalidad contra la misma por parte del Parlamento de Cataluña (17), cuya sentencia, aun no habiendo aparecido todavia, puede imaginarse ya tras haber leído la «interpretación» de la Sentencia que aquí se comenta, que coincide textualmente con la de la Ley 36/1985, de 6 de noviembre. Curiosamente, pues, en este tema una Ley del Estado ha anticipado el contenido de una Sentencia del Tribunal Constitucional, pero quien suscribe, como ya lo he manifestado, no está de acuerdo con la Sentencia ni, por tanto, tampoco con la Ley. En el siguiente punto se pondrán los fundamentos de la legitimidad constitucional de la solución que se postula.

\section{LA LEGITIMIDAD CONSTITUCIONAL DE LA LEGISLACION AUTONOMICA SOBRE LA SUPERVISION DE LA ADMINISTRACION LOCAL}

Dos órdenes de razones van a servir para fundamentar el aserto que sirve de título a este punto: el poder de autoorganización de las Comunidades Autónomas y su extensión en primer lugar $y$, en segundo, la posición de las Administraciones locales en relación a las Comunidades Autónomas.

(17) Las alegaciones del recurso del Parlamento de Cataluña se contienen en el Boletín Oficial del Parlamento de Cataluña núm. 113, de 17 de febrero de 1986, pp. 5353 y ss. El recurso viene precedido del dictamen favorable del Consejo Consultivo de la Generalidad que se publica en el Boletín nombrado, de 13 de enero de 1986. 
A) El poder de autoorganización de las Comunidades Autónomas y su extensión

La pregunta sobre el poder de autoorganización de las Comunidades Autónomas y su extensión está, es obvio, directamente relacionada con el tema que nos ocupa: los CPA y la Administración Local. Esta interrogación se deriva del siguiente punto de partida: de los diecisiete Estatutos de Autonomía, ocho conocen en su articulado [vid. nota (1)] la previsión de un CPA. ¿Significa ello que en los nueve restantes sistemas jurídicos no puede pensarse en la creación de un CPA? Dicho de otra forma: ¿la ausencia de mención en el Estatuto de Autonomía cierra la posibilidad a que una Ley ordinaria de la Comunidad Autónoma lleve a cabo la creación de una institución como la que estamos contemplando? Y si esta pregunta la respondemos afirmativamente, ¿hasta dónde podrán llegar sus competencias, su poder de supervisión?

Pues bien, desde mi punto de vista creo que no habría inconveniente en que, aun en ausencia de mención estatutaria a la figura del CPA, pudiera ésta crearse mediante una ley ordinaria. Para ello me baso en las tres siguientes razones:

La primera se deduce del carácter, de la misma naturaleza, del órgano considerado, los CPA. Aunque los Estatutos de Autonomía que recogen esta figura se refieren a la misma como parte de la "organización institucional» de la Comunidad Autónoma (18), lo cierto es que su posición en la estructura de poderes es notablemente diversa a la del Parlamento, el Presidente o el Consejo de Gobierno. Estos últimos forman el entramado básico institucional, de tal forma que cada uno de ellos es imprescindible para el funcionamiento del resto, hasta tal punto que una ausencia concreta impone lógicamente la ausencia de todos los demás. Por el contrario, los CPA, aun considerados parte de la organización institucional de la Comunidad Autónoma, son en sí derivación de la existencia del Parlamento, órganos auxiliares suyos (19) y, por tanto, su ausencia -o presencia- no afecta de forma sustancial al ser y existir del resto, no desnaturaliza el sistema de gobierno parlamentario dibujado por el Estatuto.

Quiere ello decir que la ausencia de mención del CPA en un Estatuto no puede considerarse, en modo alguno, como voluntad cerrada del legislador estatutario respecto al sistema de gobierno

(18) He llevado a cabo un minucioso estudio de la posición institucional del CPA en los distintos Estatutos de Autonomía en el capítulo primero de mi libro El control...

(19) Recoge esta terminología, entre otros, J. AGUILAR FERNÁNDEZ-HONTORIA: "A propósito del Defensor del Pueblo: Los restos definidores de la posición jurídica de los Organos auxiliares", en RAP núm. 109, 1986, pp. 7 y ss. 
creado. Este puede funcionar igual con la presencia o la ausencia del Comisionado $y$, por tanto, su introducción por vía de ley ordinaria no perturba los datos básicos plasmados en esa Ley orgánica de naturaleza especial que es el Estatuto de Autonomía. No podría considerarse entonces que fuera necesaria una reforma del Estatuto de Autonomía para introducir mediante Ley ordinaria la figura del CPA en un sistema con silencio a nivel de Estatuto de Autonomía.

Paralelamente a esta explicación debe desarrollarse la segunda de las razones que fundamentan la respuesta positiva a la interrogante planteada. La predicación constitucional de la autonomía para las Comunidades Autónomas implica la existencia de una amplísima potestad de autoorganización, y ello como consecuencia lógica del punto de partida, la autonomía (20). La creación de una institución como la del CPA debería considerarse como una muestra más del ejercicio de esa potestad de autoorganización ejercitada además mediante el máximo instrumento normativo posible en manos de la Comunidad Autónoma, la Ley (21). Esta conclusión creo que es también la congruente con los principios constitucionales sobre la competencia de las Comunidades Autónomas (22) e igualmente con la jurisprudencia del Tribunal Constitucional emitida sobre la cuestión (23). En modo alguno podría pensarse que tal creación

(20) Para un estudio general sobre la potestad de autoorganización y sus consecuencias sobre las Comunidades Autónomas, cfr. S. MUÑOZ MACHADO: Derecho público de las Comunidades Autónomas, vol. I, ed. Civitas, Madrid, 1982, pp. 67 y ss. Esta potestad de autoorganización aparece muy ampliamente considerada y valorada para cualquier clase de ente territorial del que se predique la autonomía. Un ejemplo bien claro es el del artículo 20 de la Ley de Bases de Régimen Local, de 2 de abril de 1985, donde la potestad de autoorganización sirve para que el Reglamento interno municipal pueda tẹner, incluso, una posición de superior jerarquía que la ley autonómica. El tema lo he tratado en A. EMBID IRUJO: "Ordenanzas y Reglamentos municipales», en el vol. I de Tratado de Derecho municipal, ed. Civitas, Madrid, 1988 (ed. de S. MUÑOZ MACHADO pp. 389 y ss.

(21) No serviría a estos efectos el Reglamento parlamentario, en cuanto que, aun con una naturaleza muy semejante a la de la Ley, no podría utilizarse para crear obligaciones en autoridades, funcionarios y particulares externos a la institución parlamentaria. (Sobre los reglamentos parlamentarios de los Parlamentos de las Comunidades Autónomas me remito a las pp. 68 y ss. de mi libro Los Parlamentos territoriales, junto con toda la bibliografía alli citada.) Sí que serviria el Reglamento parlamentario si se pretendiera configurar un órgano unipersonal y no colegiado, dentro del Parlamento, para recibir y tramitar las peticiones de los ciudadanos con vistas a darle una mayor agilidad que las clásicas -e ineficaces-Comisiones de Peticiones.

(22) Por ejemplo, el artículo 148.1.1 de la CE: "Las Comunidades Autónomas podrán asumir competencias en las siguientes materias: 1) Organización de sus instituciones de autogobierno.» Es arriesgado considerar al Comisionado como una «institución de autogobierno", pero sin duda el término constitucional está pensado en cualquier organismo ligado a la estructura institucional de la Comunidad: Consejos Consultivos, Sindicaturas de Cuentas, etc.

(23) Vid., por ejemplo, la Sentencia del Tribunal Constitucional 35/1982, de 14 de junio, donde se dice respecto a las instituciones de las Comunidades Autónomas, tomando como punto de partida el Consejo de Relaciones Laborales del País Vasco, que «estas instituciones son primordialmente las que el mismo Estatuto crea y que están, por ello, constitucionalmente garantizadas, pero no sólo ellas, pues la Comunidad puede crear otras en la medida en que lo 
necesitara de una actuación previa del Estado que se justificara en un título como el del artículo 149.1.18 de la Constitución, precepto que podría tener su importancia y aplicación a la hora de configurar el régimen jurídico de la actuación de la institución o de su personal, pero nunca respecto a la decisión -que debe ser absolutamente libre por parte de la Comunidad Autónoma- de creación de la institución (24).

La última de las razones a esgrimir viene deducida de una observación de Derecho comparado. En Italia, por ejemplo, una gran parte de las regiones han introducido la figura del Defensor Cívico, aun sin mención expresa en los diversos Estatutos regionales (25). Igualmente en Alemania, en un Land, Renania Palatinado, se introdujo la figura del "Comisionado de los ciudadanos" (Bürgerbeauftragte) sin mención expresa de la Constitución del Land (26).

Pues bien, defendida y, espero, demostrada la posibilidad de introducción por vía de Ley ordinaria, sin mención estatutaria, de esta figura en las Comunidades Autónomas, llega la hora de preguntarse por la extensión de sus competencias, de su poder de supervisión; en concreto, naturalmente, si la Administración local de la Comunidad Autónoma correspondiente pudiera estar sometida a ese poder de supervisión. Nótese que en este caso no existe -al revés de los supuestos contemplados anteriormente- mención estatutaria ninguna que aparentemente pueda condicionar la respuesta. Pues bien, dado que se trata de un Parlamento que mediante el ejercicio de su poder legislativo introduce un órgano auxiliar del mismo, ¿podría defenderse cumplidamente la imposibilidad de que entregara a este órgano poderes que al mismo

juzgue necesario para su propio autogobierno, en ejercicio del cual puede perseguir, como fin legítimo, el de lograr la armonía de las relaciones laborales y disminuir los conflictos a que éstas pueden eventualmente dar lugar, finalidad que es la que explícitamente persigue el Consejo de Relaciones Laborales». En la misma línea -aunque en un tono de distinta importancia políticavid. la Sentencia del mismo Tribunal 76/1984, de 29 de junio, donde se legitima la creación del Instituto Cartográfico de Cataluña.

(24) En este sentido me sumo a las críticas de MUÑoz MACHADO: Derecho Público..., pp. 71 y ss., a la Sentencia de 5 de agosto de 1983, donde se supervalora el juego del artículo 149.1.18. Igualmente, vid.: E. AJA y otros: El sistema jurídico de las Comunidades Autónomas, ed. Tecnos, Madrid, 1985, p. 290.

(25) El primer Defensor cívico introducido fue el de Toscana, con la Ley de 21 de enero de 1974, p. 8, y más adelante se han introducido los de Liguria, Ley de 6 de junio de 1974, p. 17; Lombardia, Ley de 18 de enero de 1980, p. 7; Campania, Ley de 11 de agosto de 1978. p. 23; Trento, Ley de 20 de diciembre de 1982, p. 28; Friuli, Ley de 23 de abril de 1981, p. 20; Puglia, Ley de 9 de julio de 1981; Marche, Ley de 14 de octubre de 1981, p. 29, y Piamonte, Ley de 9 de diciembre de 1981. Los datos en A. PIZZORUSSO: Lecciones de Derecho Constitucional, vol. II, ed. Centro de Estudios Constitucionales, Madrid, 1984, p. 121. También D. BuRgonovo: "ll Difensore Civico alla ricerca di un ruolo piu incisivo», en Le Regioni, 5, 1983.

(26) La introducción se hace mediante Ley de 3 de mayo de 1974, modificada por la de 5 de noviembre del mismo año. Cfr. MATTHES: Der Bürgebeauftragte, 1981. 
Parlamento pertenecen? ¿Qué duda puede caber de que un Parlamento que puede legislar creando derecho vinculante para los municipios - piénsese en el urbanismo- puede usar de sus poderes de control para supervisar la ejecución de esa legislación? (27). ¿Por qué no aceptar, entonces, que el mismo Parlamento puede encargar la supervisión del cumplimiento de esta legislación -en cuanto puedan estar afectados derechos o libertades públicas- a un órgano auxiliar, el Comisionado Parlamentario Autonómico?

Si se acepta la realidad de la existencia de un poder de autoorganización de la Comunidad Autónoma $-y$ parece difícil negarlo, dados los datos que se han proporcionado- habría que concluir en la posibilidad de creación del CPA, cuyas competencias podrían llegar hasta donde se extendieran las mismas del Parlamento: a aquellas materias en las que el Estatuto de Autonomía atribuyera competencias a la Comunidad. La falta de mención estatutaria acerca de la aparente limitación de las competencias del CPA a la supervisión de la "Administración autonómica» impediría plantearse ningún tipo de uintrepretación» acerca de la necesidad de que las competencias fueran de la Administración autonómica y hubieran sido expresamente delegadas o transferidas a los entes locales. Esta interpretación se deriva de una mención estatutaria y, en el caso que tratamos, hay ausencia total de menciones en los Estatutos.

$\mathrm{Si}$, insisto de nuevo, se acepta lo anterior, habría que concluir en que la extensión del poder de supervisión de los CPA sería potencialmente mayor en aquellos sistemas autonómicos que no hubieran previsto la existencia de esta figura $-y$ sus aparentes limitaciones- en los Estatutos de autonomía, que en aquéllos donde estuviera contemplada ya a nivel estatutario. Lo absurdo de esta conclusión obliga a pensar en la necesidad de no dejar en peor lugar a aquellos sistemas autonómicos de un mayor "interés» en esta figura (y el mayor uinterés" se deriva de la mención estatutaria) que a aquellos que callaron en el momento de la redacción de los Estatutos.

(27) Los poderes de Alta Inspección del Estado sobre las Comunidades Autónomas tienen, para E. GARCIA DE ENTERRIA el mismo fundamento de vigilancia del cumplimiento de la ejecución de una propia legislación. Salvando las evidentes distancias entre situaciones, no me parece que la cita de la idea y del autor sean irrelevantes en este lugar. Cfr. La ejecución autonómica de la legislación del Estado, en las pp. 165 y ss. de Estudios sobre Autonomias Territoriales, ed. Civitas, Madrid, 1985. 


\section{B) La posición de la Administración local en las Comunidades Autónomas}

Pero la anterior explicación es todavía coja, necesita complementarse con un breve escurso acerca de la posición que en las Comunidades Autónomas tienen las Administraciones Locales. El objeto de este breve tratamiento será mostrar como la conclusión anterior -posibilidad del CPA de supervisar la actividad de las Administraciones locales cuando actúen dentro de las competencias que se otorgan a la Comunidad Autónoma en el Estatuto de Autonomía no choca ni es desmentida por la posición jurídica que las entidades locales tienen dentro de las Comunidades Autónomas.

El tema, quizá discutible en el pasado, no presente hoy excesivas dificultades. Así, hay que decir que es comúnmente aceptado el hecho de que la Administración local se encuentra a caballo entre el Estado y las Comunidades Autónomas (28). Es obvio que frente a las exigencias formales de algunos Estatutos de Autonomía (29) no puede aceptarse que las Administraciones locales hayan sido uinteriorizadas» por completo por la Comunidad Autónoma (30). Pero tampoco puede defenderse, con base en una lectura unilateral del art. 137 de la Constitución (31), que las Administraciones locales si sitúen fuera del círculo de competencias e intereses de las Comunidades Autónomas. Como muy bien ha deducido la doctrina española siguiendo los dictados de la más avanzada doctrina germánica $(32)$, lo que sucede es que el «régimen local» no tiene una consideración univoca y que, por tanto, si en cuestiones organizativas el referente fundamental para la Administración Local es la actividad de la Comunidad Autónoma bien que sujeta a la bases establecidas por el Estado (33), en los

(28) Vid. la muy detenida exposición de L. PAREJO ALFONSO: Estado social y Administración pública. Los postulados constitucionales de la reforma administrativa, ed. Civitas, Madrid, 1983, pp. 150 y ss.; también S. MUÑOZ MACHADO: Derecho público de las Comunidades Autónomas, vol. Il, ed. Civitas, Madrid, 1984, pp. 182 y ss.

(29) Vid., por ejemplo, el artículo 5.1 del Estatuto de Cataluña: «La Generalidad de Cataluña estructura su organización territorial en municipios y comarcas, también podrá crear demarcaciones supracomarcales.»

(30) Cfr. L. PAREJO ALFONSO: Estado social..., p. 189, que se refiere a la interiorización por las Comunidades Autónomas a través de los Estatutos de Autonomía desde el punto de vista orgánico.

(31) Reproduzco el texto del precepto citado: «El Estado se organiza territorialmente en municipios, en provincias y en las Comunidades Autónomas que se constituyan. Todas estas entidades gozan de autonomia para la gestión de sus respectivos intereses.)

(32) La obra que se toma como punto de referencia es la de J. BURMEISTER: Verfassungstheoretische Neukonzeption der kommunalen Selbstverwaltungsgarantie, Verlag Vahlen, München, 1977.

(33) Cfr. L. PAREJo Alfonso: Estado social..., pp. 185 y ss., y S. MUÑoz MACHADO: Derecho público..., pp. 187 y ss. 
ámbitos materiales las fuentes normativas pueden provenir tanto del Estado como de las Comunidades Autónomas. La Sentencia del Tribunal Constitucional 84/1982, de 23 de diciembre, ha resumido con una cita que, por repetida, ha hecho fortuna, la posición de las Administraciones Locales:

«Este carácter bifronte del régimen jurídico de las autonomías locales en algunas Comunidades Autónomas, que hace imposible calificarlo de forma unívoca como "intracomunitario" o "extracomunitario", no es contradictorio con la naturaleza que a las entidades locales atribuye la Constitución, cuyo artículo 137 concibe a municipios y provincias como elementos de división y organización del territorio del Estado. Dividido y organizado, también éste, en su integridad y sin mengua de ella en Comunidades Autónomas, ambas formas de organización se superponen sin anularse $y$, si bien el grado superior de autonomía, que es el propio de las Comunidades, les otorga potencialmente un poder político y administrativo sobre los municipios y provincias que se incluyen en su territorio, éstas y aquéllos no desaparecen ni se convierten en meras divisiones territoriales para el cumplimiento de los fines de la Comunidad, aunque puedan cumplir también esta función» (del fundamento jurídico núm. 4).

La Ley de Bases de Régimen Local, Ley 7/1985, de 2 de abril, refleja perfectamente este carácter bifronte a lo largo de su estructura y articulado, pero, sobre todo, en un artículo capital a estos efectos, como es el $5 .^{\circ}$, en el que se indican las fuentes normativas para las entidades locales, distinguiendo según se trate de organización, servicios, bienes, funcionarios, Haciendas, etc. (34).

Todo lo dicho hasta ahora creo que justifica más que sobradamente el contenido de las Leyes ordinarias de las Comunidades Autónomas citadas -por supuesto el de la Ley aragonesa reguladora del Justicia de Aragón- y su voluntad de entregar la supervisión de la actividad de la Administración local, en las materias propias de la competencia de la Comunidad Autónoma, a los CPA. $\mathrm{Si}$ en el ámbito organizativo la posición de las Administraciones locales está prácticamente vinculada por las potestades de la Comunidad Autónoma, y en el competencial se produce, al menos, una copartición de las relaciones, no es extraordinario que en

(34) En la doctrina más reciente vid. las pp. 148 y ss. de L. MORELL OCAÑA: El Régimen Local español, ed. Civitas, Madrid, 1988. Igualmente los trabajos de BAÑO LEON. EMBIO IRUJO y FERNÁNDEZ FARRERES contenidos en el Tratado..., cit. en nota 20. 
aquellos ámbitos donde puede defenderse que las Administraciones locales han sido «interiorizadas» por la Comunidad Autónoma, ésta, en uso de su poder, otorgue competencias de supervisión al CPA. $Y$ ello, sin tener en cuenta otra cosa que el sistema constitucional y estatutario vigente, la situación actual y sin plantearse, tampoco, ninguna estrategia en función de la previsible orientación de las cosas (35). Había, por tanto, legitimidad constitucional en la Ley reguladora del Justicia de Aragón -como la hay en las otras leyes autonómicas- y la actividad "interpretadora» del Tribunal Constitucional, aun perfectamente posible, era en este caso superflua, puesto que la norma sujeta al recurso de inconstitucionalidad estaba adecuada a la Constitución, y no precisaba, por tanto, de ninguna interpretación. Dicho sea todo esto, por supuesto, con el máximo respeto al Tribunal y a su meritoria e impagable labor de enaltecimiento del respeto a la Constitución.

\section{REFLEXIONES FINALES}

Aun cuando el comentario a la Sentencia ya ha sido concluido, no querría terminar este trabajo sin formular tres reflexiones motivadas, es obvio, por la Sentencia y la problemática jurídica que encierra.

Creo que, en primer lugar, debe hacerse especial hincapié en la dificultad práctica del cumplimiento efectivo del criterio de interpretación realizado por el Tribunal Constitucional. En efecto, la competencia del CPA se hace depender -en lo que a la Administración local se refiere- de la existencia de una transferencia o delegación de competencia de la Administración autonómica en la Administración local. Pues bien, este criterio es sumamente indeterminado, pues excepto en el caso de las Diputaciones Provinciales, donde el ordenamiento jurídico indica la necesidad de que las transferencias o delegaciones de competencias se efectúen para la totalidad de las Diputaciones Provinciales (36), es perfectamente posible que para

(35) Recuerdo, simplemente, las palabras de MUÑoz MACHADO cada día más válidas a estos efectos: «El tiempo terminará por imponer que el grueso de la vida de relación de los entes locales con las Administraciones superiores vendrá constituido por las que mantengan con las Comunidades Autónomas.» Cfr. p. 193 de Derecho público... En el mismo sentido PAREJO ALFONSO: "Todo lo dicho conduce a la afirmación final de que el ordenamiento infraconstitucional (...) ha de configurar y construir, asi como, en su caso, contemplar o tratar a la Administración local como una pieza orqanizativa de la estructura territorial de las Comunidades Autónomas, sin perjuicio de su capacidad de mantenimiento de relaciones directas con la Administración del Estado. La legislación posconstitucional ha de partir, pues, de esta comprobación fundamental». Cfr. Estado social..., pp. 190 y 191.

(36) Este mandato se contiene en el artículo 5.1 de la Ley 12/1983, de 14 de octubre, del proceso autonómico. Por cierto, que este mandato de "generalidad» en la delegación no aparece en el artículo 37.1 de la Ley 7/1985, de 2 de abril, reguladora de las Bases del Régimen Local 
los Municipios haya delegaciones singulares, no generales, que se fundamenten en el tamaño del Municipio, su riqueza económica, su posibilidad de prestar servicios, su situación geográfica, etc. Quiere ello decir que en muchas ocasiones será imposible en un determinado caso responder sin vacilaciones sobre la posibilidad de supervisión del CPA de una Corporación local concreta. Sólo la consulta detenida del Boletín Oficial de la Comunidad correspondiente podría ofrecer una respuesta segura. Cuando se piensa en la flexibilidad, en la simplificación que debe presidir la forma de actuación de órganos como los CPA, se advierte las dificultades que para el ciudadano puede tener un criterio de interpretación como el expuesto. Difícilmente, ante una actuación de una Corporación local, se preguntará el ciudadano que pretenda presentar una queja, si ésta ha sido ejercitada dentro de una competencia que haya sido delegada o transferida por la Comunidad Autónoma, o que se ejercite dentro del ámbito propio de competencia de la Corporación local. Lo que se hará, si pretende presentar una queja ante el CPA, será presentarla sin preguntarse nada más.

Desde la posición del CPA lo único que quedará, entonces, será examinar la queja, investigar si ha tenido lugar esa transferencia o delegación y, en caso negativo, enviarla inmediatamente al Defensor del Pueblo dando cuenta al ciudadano concreto de ese envío. No es, precisamente, una posición muy brillante ni tampoco efectiva, pero de ello hablaré más adelante.

Estoy hablando en general de los CPA. Pero es obvio que la Sentencia comentada se refiere solamente al Justicia de Aragón, y la interpretación -que llamo restrictiva- fundamentada por el Tribunal Constitucional, es predicable en principio sólo para él. En torno a esta cuestión querría centrar la segunda reflexión.

Quien haya consultado la primera nota de este trabajo habrá podido leer en ella las fechas de promulgación de las Leyes ordinarias autonómicas reguladoras de los respectivos CPA. Las, hasta ahora, seis leyes vigentes se promulgan entre los años 1983 y 1985. La Ley reguladora del Justicia de Aragón es, precisamente, la última de las promulgadas, y se aprueba el 27 de junio de 1985. Llama la atención, entonces, que haya sido ella la recurrida ante el

donde simplemente se indica la posibilidad de delegación en las Diputaciones de competencias de las Comunidades Autónomas. (El artículo 37.2 se refiere a delegación de competencias del Estado.) Podía legítimamente plantearse la posibilidad de derogación del precepto de la Ley del proceso autonómico por la Ley de Bases de Régimen Local y; probablemente, ello sería la conclusión más acertada, aunque no puede afirmarse con rotundidad. En cualquier caso, he preferido optar en este trabajo por la seguridad que proporciona un precepto escrito no formalmente derogado, pero he de advertir que afirmar la solución contraria no sólo no modificaría, sino que, por el contrario, reforzaría la tesis general sobre la inseguridad del criterio interpretativo del Tribunal Constitucional, que se defiende en el texto. 
Tribunal Constitucional, sin que hubiera existido recurso contra leyes anteriores, como la vasca, catalana o canaria, que en esta cuestión presentaban una redacción semejante. Desde otro punto de vista, podría plantearse la interrogación acerca de si el criterio interpretativo sentado por el Tribunal Constitucional en esta Sentencia, afecta al régimen jurídico de los otros CPA. Respondamos a estas cuestiones.

En cuanto a la presentación "tardía» de un recurso de inconstitucionalidad y su ausencia en casos anteriores pretendidamente semejantes, no puede hacerse otra cosa que constatar el hecho sin que puedan deducirse ningún tipo de conclusiones jurídicas. La presentación de un recurso de inconstitucionalidad pertenece al ámbito de libre disposición de quienes poseen legitimación, por prescripción constitucional, para ello. En última instancia, se traduce de una determinación política, y ésta puede ser cambiante por el transcurso del tiempo, tanto porque varien las circunstancias fácticas, como porque se dé una modificación en la composición -en el caso de órganos compuestos, como las Asambleas de las CC AA- personal de quienes integran el órgano de legitimación para recurrir. Por el motivo que fuere no se interpuso el recurso hasta que se promulgó la última de las leyes recurridas, la aragonesa, y de ello, repito, no hay ninguna conclusión jurídica que extraer.

No es ajena al Tribunal Constitucional la segunda de las problemáticas expuestas, la posible afección a otros CPA de la interpretación que se defiende en la presente Sentencia, y a ella responde según lo que es doctrina lógicamente deducible del ordenamiento jurídico vigente $y$ de la tradicional jurisprudencia del mismo Tribunal.

«Añaden a dicha argumentación (los representantes de las Cortes de Aragón y de la Diputación General) que, por otra parte, las facultades que este apartado del artículo 2 atribuye al Justicia, son similares a las que otras leyes autonómicas asignan a la misma Institución en sus respectivas Comunidades, haciendo referencia expresa al Síndico de Greuges de la Generalidad de Cataluña, al Ararteko del Pais Vasco y al Diputado del Común de la Comunidad Canaria. Prescindiendo de esta última argumentación, porque el juicio de constitucionalidad ha de hacerse, como viene declarando con reiteración este Tribunal, con base a la Constitución y en el Estatuto de Autonomía correspondiente a la Comunidad de que se trate en cada caso, y no 
en lo dispuesto en otras leyes, pasamos a examinar el problema de fondo planteado sobre la constitucionalidad del precepto» (del fundamento jurídico quinto).

Es clara, por tanto, la falta de efectos directamente deducibles de esta Sentencia para el régimen jurídico de los otros CPA. Podríamos decir, entonces, que tras la Sentencia convivirían dos regímenes jurídicos distintos en cuanto se refiere a la supervisión de la Administración local por los CPA: el del Justicia de Aragón, restringido, y el de los otros CPA, amplio en cuanto que sus leyes reguladoras no han sido recurridas.

Esta conclusión, aun aparentemente aberrante (37) podría ser cierta de no haber tenido lugar la promulgación de la Ley 36/1985, de 6 de noviembre, por la que se regulan las relaciones éntre la Institución del Defensor del Pueblo y las figuras similares en las distintas Comunidades Autónomas. Como se recordará de las páginas anteriores, esta Ley, en virtud de un sibilino cambio durante su tramitación parlamentaria, "anticipó» en su artículo 2.1 lo que hoy es interpretación del Tribunal Constitucional. Por ello, la afección al régimen jurídico del resto de CPA no se produce mediante la aparición de la Sentencia del Tribunal Constitucional que nos ocupa, sino vía la Ley 36/1985, de 6 de noviembre, que, como se recordará también, fue recurrida por el Parlamento de Cataluña, a fin de evitar ese resultado, recurso que, por cierto, aún no ha sido fallado, si bien el contenido de esta Sentencia permite anticipar el contenido del fallo (38).

Por fin, sólo quiero hacer constar que la afirmación del tenor de la ley aragonesa $-y$ de las restantes leyes autonómicas- en nada hubiera impedido o menoscabado el ejercicio de las competencias que por afirmación de la Constitución corresponden al Defensor del Pueblo. A nadie se le oculta que esta Institución extrae de la Constitución su más alta legitimidad, y que las competencias de interposición del recurso de amparo y del de inconstitucionalidad, le sitúan en una posición en modo alguno comparable con la de los CPA que no disponen de ningún remedio procesal activo propio

(37) Una conclusión que, por otra parte, tiene lugar usualmente cuando se recurren preceptos de unas Comunidades Autónomas y no de otras, o cuando aparecen antes unas sentencias que otras. En esos supuestos una posible vía de solución, para llegar a pronunciar la inconstitucionalidad de todas las disposiciones semejantes, es que se operara por la vía de las cuestiones de inconstitucionalidad, lo que permitiría al Tribunal Constitucional fallar con su primitiva doctrina casos semejantes. Esta vía de solución presupone la posibilidad de «jurisdiccionalización» de la materia correspondiente, lo que no parece posible en el caso que nos ocupa.

(38) Si, por los motivos que fuera, la Sentencia del Tribunal Constitucional en el recurso del Parlamento catalán fuera afirmativa de las razones de éste, se habría producido en realidad la dicotomía de régimen jurídico a que me refiero en el texto: para un CPA -el aragonés- la interpretación restrictiva, para el resto el tenor de sus propias leyes ordinarias. 
para el ejercicio de sus competencias, sino que deben contar, necesariamente, con la intervención del Defensor del Pueblo para ello, quedando en el ámbito de discrecionalidad de esta Institución la interposición, o no, de los recursos.

En nada se hubiera visto afectado o menoscabado, repito, el prestigio y efectividad de esta Institución y es posible, incluso, que afirmar la legitimidad constitucional de la ley aragonesa hubiera cooperado a una mejor efectividad de la protección de los derechos y libertades de los españoles si el sistema de convenios a que se refiere la Ley 36/1985, de 6 de noviembre, hubiera sido puesto en práctica y facilitara un funcionamiento ágil y nada burocrático de la protección de los derechos. Digo esto, evidentemente, a título de interrogación y de duda personal, pues difícilmente se hallarán parámetros que permitan responder con seguridad a tamaña inquisición. En cualquier caso, ello es adjetivo respecto al verdadero objeto de estas páginas, exclusivamente jurídico y destinado a discurrir sobre un aspecto menor, no capital, desde luego, pero, como tantos otros, de necesaria consideración para una vigencia lozana y juvenil de nuestra Constitución, que está a punto de cumplir diez años. 